\title{
Implantation of Perceval valve in mitral position: A new technique
}

Marcin Szczechowicz, MD, Ahmed Mashhour, MBBCh, Onise Chaduneli, MD, and Alexander Weymann, MD, PhD, FECTS, FESC, Oldenburg, Germany

From the Department of Cardiac Surgery, Oldenburg University Hospital, European Medical School Oldenburg-Groningen, Oldenburg, Germany.

This work was not financially supported.

Disclosures: Authors have nothing to disclose with regard to commercial support.

Received for publication May 26, 2018; revisions received July 14, 2018; accepted for publication July 18, 2018; available ahead of print Sept 1, 2018.

Address for reprints: Marcin Szczechowicz, MD, Department of Cardiac Surgery, Oldenburg University Hospital,

Rahel-Straus-Strasse 10, 26133 Oldenburg, Germany (E-mail: marcin.szczechowicz@yahoo.com).

J Thorac Cardiovasc Surg 2019;157:225-8

$0022-5223 / \$ 36.00$

Copyright (C) 2018 by The American Association for Thoracic Surgery

https://doi.org/10.1016/j.jtcvs.2018.07.057

Video clip is available online.

A 62-year-old female patient who had not previously undergone any heart operations was referred to our clinic by a peripheral hospital for acute mitral valve endocarditis with a septic course, which was accompanied by valve regurgitation and myocardial infarction. She had been resuscitated several times because of pulseless ventricular tachycardia and mechanically ventilated for 2 weeks because of fulminant pneumonia and acute respiratory distress syndrome. Atrial fibrillation with a ventricular frequency of 110 beats/min had been seen for several weeks. The tracheal smear showed Candida albicans, and the

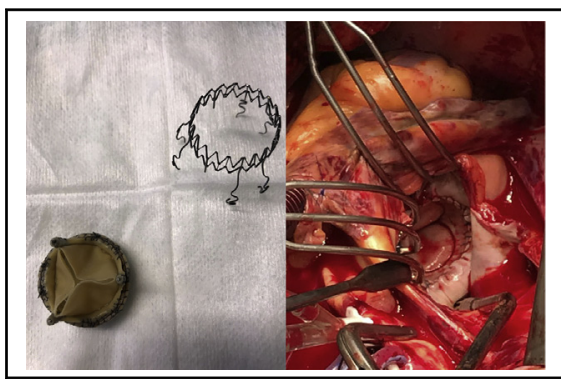

Left, Perceval valve after removal of the stent cage. Right, Implanted in the mitral position.

\section{Central Message}

It is possible to implant the Perceval valve offlabel in the mitral position in selected cases, especially when the ring is small and destroyed by infection.

See Editorial Commentary page 229.
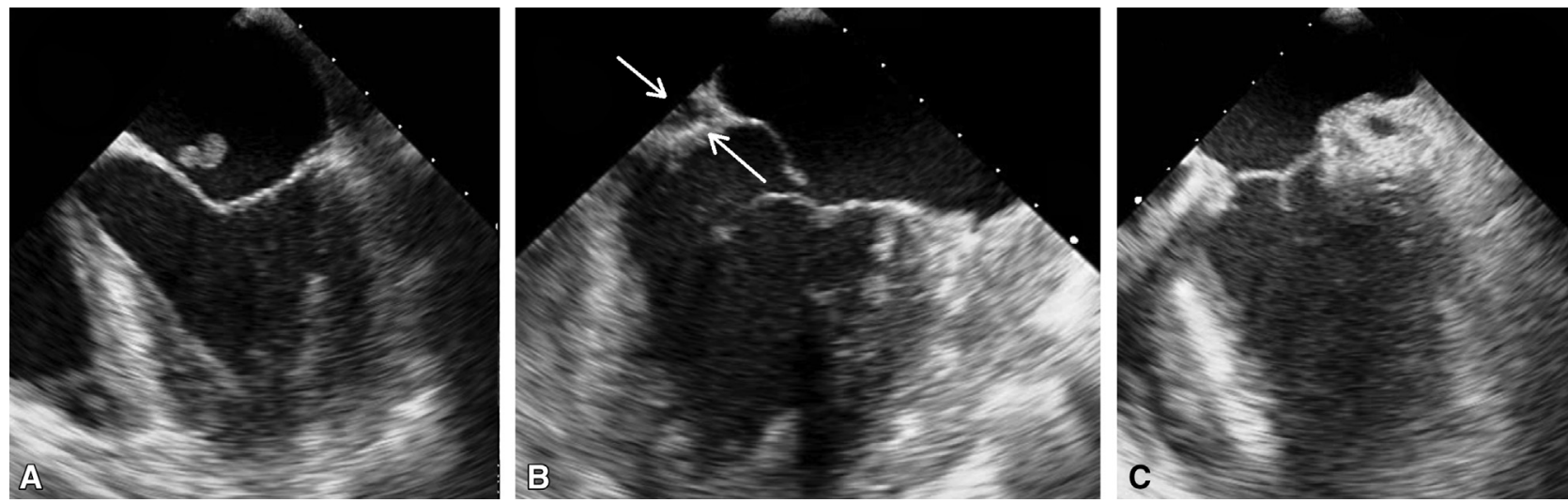

FIGURE 1. Transesophageal echocardiography. A, Vegetation on the anterior mitral leaflet. B, Ring abscess (white arrow) C, Perceval valve (LivaNova PLC, London, UK) in the mitral position. 

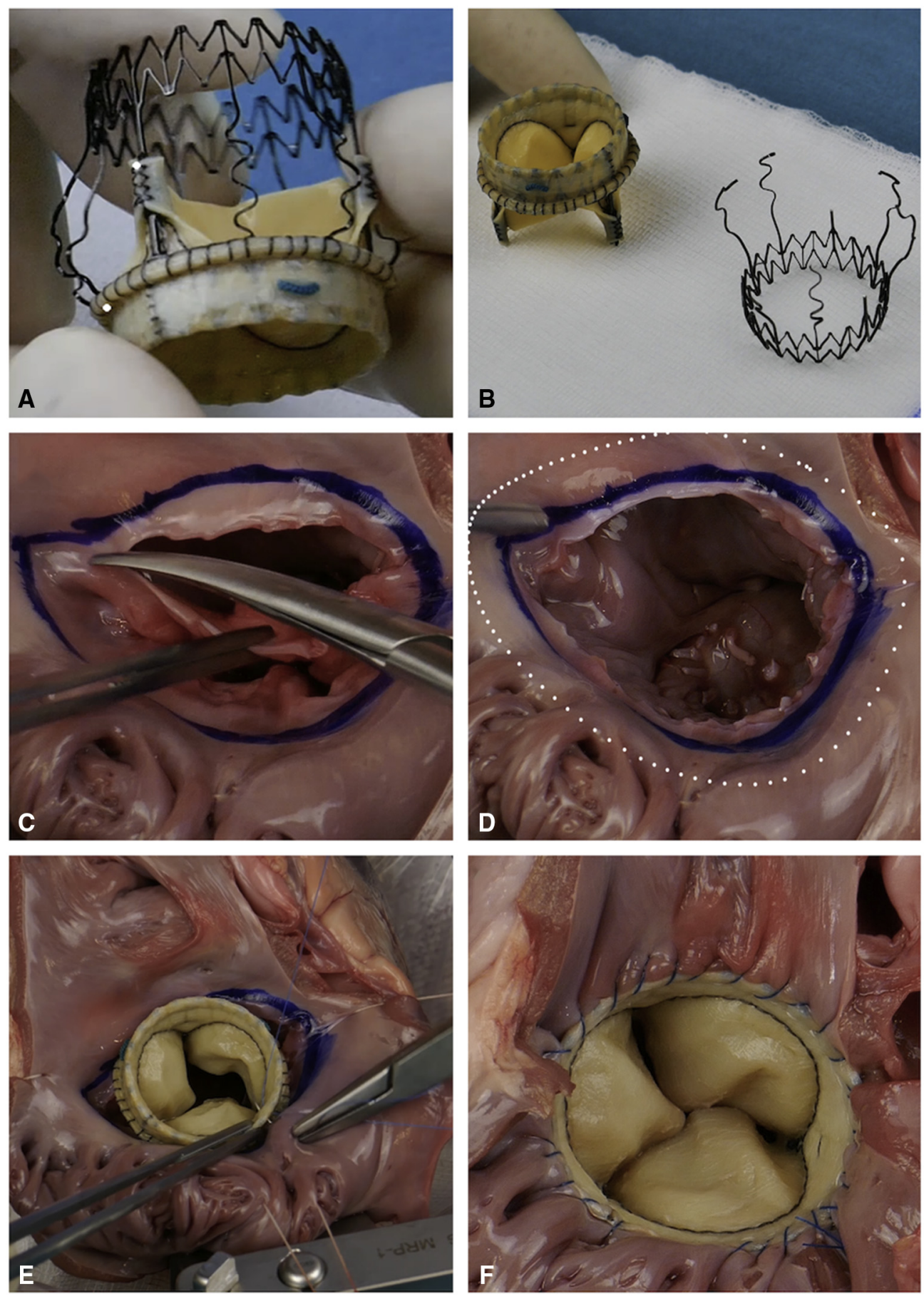

FIGURE 2. Technique of implantation on a porcine heart model, view of the opened left atrium. A, The Perceval prosthesis (LivaNova PLC, London, UK). $\mathrm{B}$, The stent is cut off. C, Leaflets are resected. The anatomic ring is marked with the blue line. $\mathrm{D}$, The suture line above the ring is marked with the white dotted line. E, The sutures are placed. F, The implanted valve can be seen in situ.

infective endocarditis also in this location. Moreover, coronary angiography showed a significant 3 -vessel disease. Antimicrobial therapy was introduced in accordance with guidelines. The patient was urgently prepared for surgery. On the cardiopulmonary bypass, crystalloid cardioplegia was given. As soon as the isoelectric electrocardiogram was achieved, the high-frequency biatrial ablation with isolation of the left auricle was done. Next, we performed the sequential coronary artery bypass grafting of the left anterior descending and first marginal branch by using the 


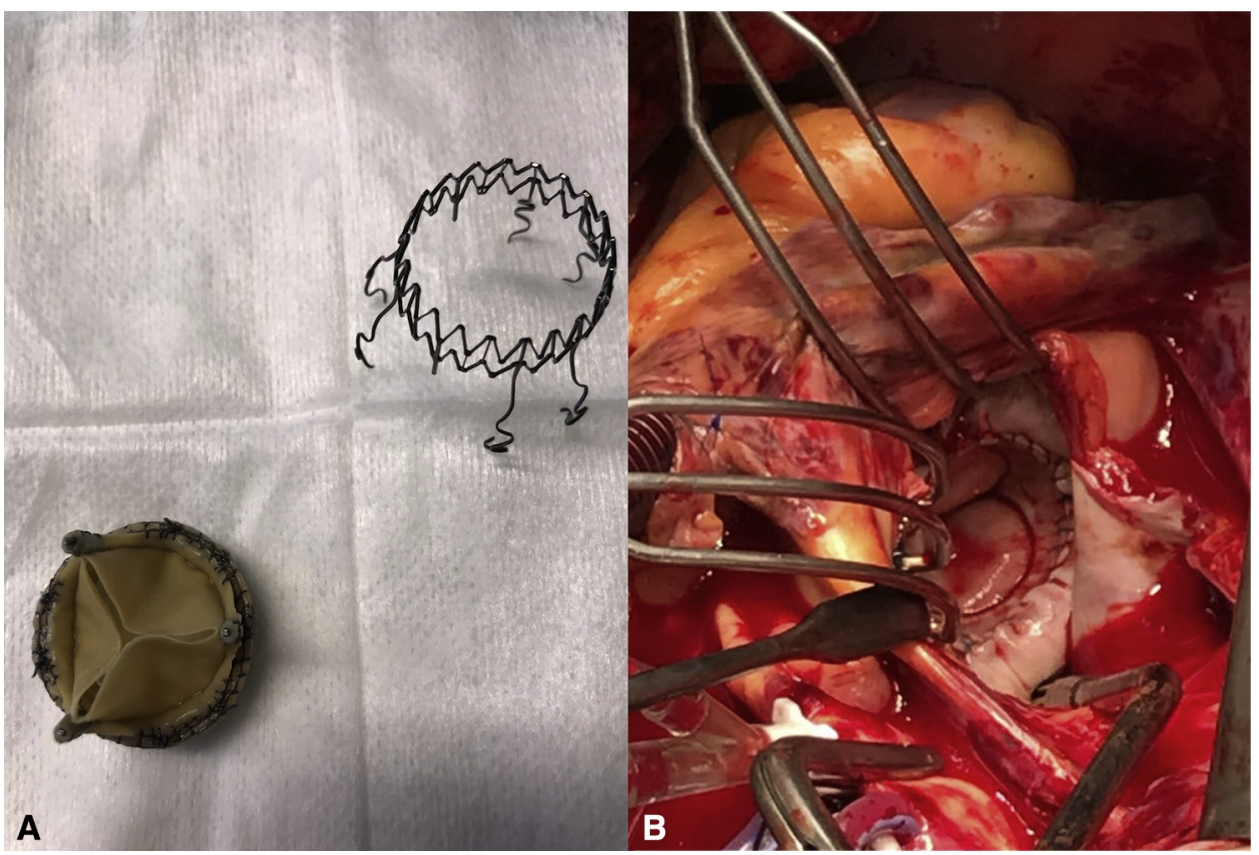

FIGURE 3. A, Perceval valve (LivaNova PLC, London, UK) after removal of the stent cage. B, Implanted in the mitral position.

great saphenous vein. We did not use the internal thoracic artery because of the last-chance nature of the surgery and severe respiratory failure with barotrauma after providing mechanical ventilation for a long time. The right coronary artery was very small, calcified, and not suitable for bypass grafting. The left atrium was opened anterior to right pulmonary veins.

There was a $1-\mathrm{cm}$ round vegetation attached to the anterior mitral leaflet. A patent foramen ovale was closed with a single suture. While removing the mitral leaflets,

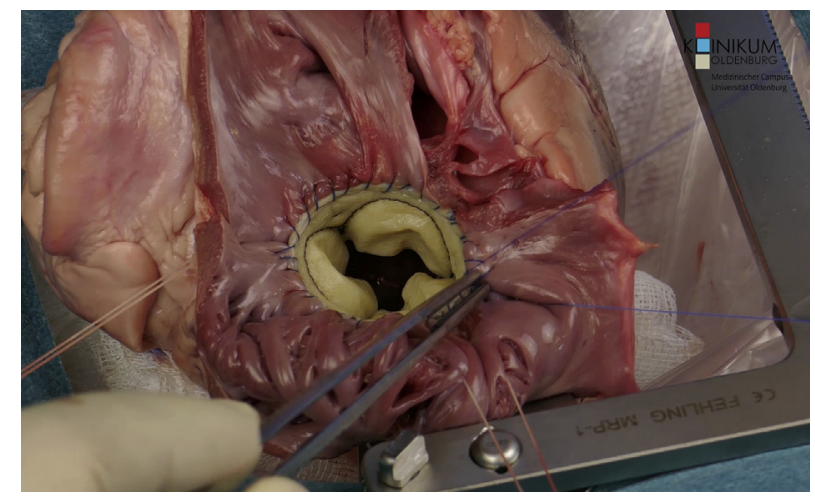

VIDEO 1. The preparation of the Perceval valve (LivaNova PLC, London, UK) and implantation technique are shown on the isolated porcine heart. $A M L$, Anterior mitral leaflet; $P M L$, posterior mitral leaflet. Video available at: https://www.jtcvs.org/article/S0022-5223(18)32049-X/fulltext. we opened a large abscess at the anterior aspect of the ring. The posterior aspect was severely destroyed as well. A thorough débridement of the annulus was carefully done.

Sizing of the valve revealed a very small ring, so that even a $27-\mathrm{mm}$ sizer did not pass through the valve. Because of extensive destruction of the ring, we decided to implant a Perceval XL prosthesis (LivaNova PLC, London, UK) as the last option. The stent was cut off, and the valve was implanted upside down with a 4.0 continuous Prolene (Ethicon, Inc, Somerville, NJ) suture (Figures 2 and 3 and Video 1). The suture line was placed about $5 \mathrm{~mm}$ from the former mitral annulus toward the left atrial cavity. After atrium closure, we inspected the aortic valve, which presented no pathology. The crossclamp was released, and sinus rhythm began spontaneously. We completed the central anastomosis of the coronary bypass. The circulation was stabilized with low-dose norepinephrine, and the cardiopulmonary bypass could be stopped. Transesophageal echocardiography showed a well-functioning prosthesis (Figure 1). There were no major postoperative complications. The mean gradient through the prosthesis was $4 \mathrm{~mm} \mathrm{Hg}$.

To our knowledge, this is the first case of implantation of the Perceval valve in the mitral position. We chose this way because of the extensive ring destruction and its very small diameter. The tissue collar surrounding this prosthesis was perfect to be placed in the destroyed ring. Precise removal of the stent is very important so that there are no sharp 
elements left. The continuous suture technique enabled us to position the valve very precisely. In addition, the amount of foreign material was minimal, which is crucially important in such heavily infected, friable tissue. In case of infection recurrence, a simple prosthesis replacement after removing the continuous suture would be theoretically possible. The other advantage of our technique is shortening of the crossclamp time, which was, in our case, 56 minutes and would probably have been longer had other techniques with extensive patch reconstruction of the annulus been used.

In our patient, the anulus was also too small for every other available prosthesis. It would have been theoretically possible to implant another stented aortic valve prosthesis in the mitral position, but rigidity and a ring made of a foreign material would not be fit for this purpose.

The advantages of the Perceval valve prosthesis are minimal gradients, good durability, and mechanical flexibility. ${ }^{1-4}$ It is therefore possible to implant the Perceval valve off-label in the mitral position after a preprocessing in selected cases, especially when the ring is extremely small and destroyed by infection. Foreign material is kept to a minimum.

\section{References}

1. Stoker T, Mashhour A, Easo J, Kronberg K, Ennker J, Weymann A. Novel treatment of a degenerated bioroot with the use of the sutureless valve technique. Ann Thorac Surg. 2018;105:e213-4.

2. Laborde F, Fischlein T, Hakim-Meibodi K, Misfeld M, Carrel T, Zembala M, et al. Cavalier Trial Investigators. Clinical and haemodynamic outcomes in 658 patients receiving the Perceval sutureless aortic valve: early results from a prospective European multicentre study (the Cavalier Trial) $\dagger$. Eur J Cardiothorac Surg. 2016;49: 978-86.

3. Meuris B, Flameng WJ, Laborde F, Folliguet TA, Haverich A, Shrestha M. Fiveyear results of the pilot trial of a sutureless valve. J Thorac Cardiovasc Surg. 2015; 150:84-8.

4. Baran C, Durdu MS, Gumus F, Cakici M, Inan MB, Sirlak M, et al. Sutureless aortic valve replacement with concomitant valvular surgery. J Thorac Cardiovasc Surg. 2018;155:2414-22. 